\title{
ENT-Related Islamic Instructions
}

\author{
Hesham Elmashad* \\ Medical Director, Saudi Arabiah \\ *Corresponding author: Hesham Elmashad, ENT consultant, Medical director, Saudi Arabia, \\ Submission: 望 February 22, 2018; Published: 海 February 27, 2018
}

\section{Perspective}

There are many Islamic instructions that can prevent and/or treat some ENT-related diseases. The splendor of these instructions is that they are not exclusive for Muslims, on the contrary they can be applied by anyone, Muslim or non- Muslim.

In addition to this vital concept, these instructions have other important criteria:
1) Extremely effective.
2) Easily applicable.
3) Highly cost effective.
4) Nearly with no side effects.

These advantages made me anxious and keen to share these knowledges with my ENT colleagues in this important conference, to help them in treating their patients. Islamic instructions addressed many diseases like sinusitis, obstructive sleep apnea, halitosis and others...

\section{Sinusitis}

It's well known that the most important step in the treatment of sinusitis, either medical or even surgical, is the nasal wash. Nasal wash to be effective must be deep and frequent. For this purpose, they invented many pumps [1,2].

How does Islam treat this problem?? By ablution (Wudoo): It's just washing with water, by which Muslims clean their organs externally, preparing themselves to pray hoping to be cleaned internally.... Islam asks Muslims to do ablution several times through the 24 hours. When Prophet Mohammad, peace be upon him, taught Muslims ablution, he said: "exaggerate in nasal wash till water may reach the nasopharynx, unless you are fasting" Narrated by the five and corrected by al-Tirmizi))

\section{Obstructive Sleep Apnea}

It's described as intermittent cessation of airflow during sleep that lasts $\geq 10$ seconds. It's very dangerous disease that deprives patient from normal sleep that may lead to daytime somnolence with more liability for car accidents.

According to most recent literatures, the treatment is divided into three categories:
a) 1-Behavioral Modifications.
b) 2-Physical intervention.
c) 3-Surgical intervention.

Behavioral Modifications consists of:

a. Weight loss; by dieting and exercises or by briatric surgery for severe cases [3].

b. Sleeping positions: encourage lateral sleep positions $[4,5]$.

How Does Islam Treat This Problem??

By 2 means

\section{Encourage weight loss, through 3 texts}

A. Quran Kareem: "O children of Adam, take your adornment at every masjid, and Eat and drink, but be not excessive. Indeed, He likes not those who commit excess."

B. Hadith Sharif "Prophet's talk":" Son of Adam does not fill bowl worse than his stomach, small bits are enough for him, but if he has to fill it, then, one third for his food, one third for his drink and one third for his breath" (Narrated and corrected by al-tirmithi)

C. Gnomic words: "We are people who do not eat until being hungry and if we eat we do not eat to the extent of satisfaction"

\section{Encourage lateral sleep position}

"If one of you shelter to his bed, he has to clean it with his garment, because he does not know what is left behind him, and then Sleep on his right side, then say: "By Your Name, my Lord I put my side and By Your Name I raise it up, if You hold my soul have mercy on it." (Narrated by Bukhari, Muslim and Abu Dawood)

\section{Halitosis}

Halitosis: is bad breath can result from poor dental health habits and may be a sign of other health problems as sinusitis, caries, smoking $\&$ alcohol or as a result of eating some foods like onion or garlic [6].

\section{How Does Islam Treat This Problem?}

By three instructions 


\section{Frequent use of SEWAK (or miswak):}

It's a toothbrush-like tool of plant origin with good flavor and anticaries effects. Its scientific name is Salvadora persica. The World Health Organization (WHO) recommended the use of the miswak in 1986 [7].

In 2003, a scientific study comparing the use of miswak with ordinary toothbrushes concluded that the results clearly were in favor of the users who had been using the miswak, provided they had been given proper instruction in how to use it [8].

The Prophet, peace be upon him, said:" Unless it will be difficult for my people, I'll order them to use sewak at every prayer ". Narrated by al bukhari and muslim.

\section{Advises muslims not to eat onion or garlic before meetings}

The Prophet, peace be upon him, said: "Whoever eats garlic or onion he must avoid us or avoid our mosque, and stay in his home" (narrated by al bukhari)

\section{Prohibit smoking and alcohol}

Quran Kareem: "Ye who believe: intoxicants and gambling, (dedication of) stones, and (divination by) arrows, are an abomination, of Satan's handiwork: eschew such (abomination), that ye may prosper." (5- 90)

\section{Critical question??}

If this is true.Why many Muslims suffer from these diseases?

This is because not all Muslims follow strictly these instructions.

On the contrary, if non Muslims follow these instructions they will not only cure from these diseases but get protected also.

To summarize these details, the Islamic instructions related to:

a) Sinusitis: excessive and frequent nasal wash during wudoo (ablution).

b) Obstructive sleep apnea (OSA): encouraging weight reduction and lateral sleep positions. c) Halitosis: frequent use of sewak and mouth rinsing during wudoo together with prohibiting smoking \& alcohol and avoidance of eating garlic or onion before meetings.

\section{Recommendations}

Although the effects of these instructions were fully investigated, this is an open invitation for both supporters \& opponents to do more and more scientific researches, because these which will be done by the supporters will verify and ensure the effectiveness of these Islamic instructions. While those which will be done by the opponents will avoid religious bias which we may be accused with.

\section{Conclusion}

Muslims or Non Muslims, if they did not follow these instructions, they must blame no one except themselves. Muslims or Non Muslims, if they follow these instructions strictly, they will gain, much more than they expect... I promise.

\section{References}

1. Daviskas E, Anderson SD, Gonda I, Eberl S, Meikle S, et al. (1996) Inhalation of hypertonic saline aerosol enhances mucociliary clearance in asthmatic and healthy subjects. Eur Respir J 9(4):725-732.

2. Heatley DG, McConnell KE, Kille TL, Leverson GE (2001) Nasal irrigation for the alleviation of sinonasal symptoms. Otolaryngol Head Neck Surg 125(1): 44-48.

3. Strobel RJ, Rosen RC (1996) Obesity and weight loss in obstructive sleep apnea: a critical review. Sleep 19(2): 104-115.

4. Kavey NB, Blitzer A, Gidro-Frank S, Korstanje K (1985) Sleeping position and sleep apnea syndrome. Am J Otolaryngol 6(5): 373-377.

5. Cartwright RD, Lloyd S, Lilie J, Kravitz H (1985) Sleep position training as treatment for sleep apnea syndrome: a preliminary study. Sleep 8(2): 87-94.

6. Nachnani S (2011) Oral malodor: Causes, assessment, and treatment. Compend Contin Educ Dent 32(1): 22-24, 26-8, 30-1; quiz 32, 34.

7. Darout IA (2003) Examination of an actual ancient mouth cleaning method.

8. Al-Otaibi M, Al-Harthy M, Soder B, Gustafsson A, Angmar-Mansson B, et al. (2003) Comparative effect of chewing sticks and toothbrushing on plaque removal and gingival health. Oral Health Prev Dent 1(4): $301-$ 307.

Your subsequent submission with Crimson Publishers will attain the below benefits

Creative Commons Attribution 4.0 International License 